\title{
Questionnaires done with specialists and residents on factors that may affect bonding strength during bonding procedure in orthodontics
}

\author{
Mahmoud El Saafin ${ }^{1}$, Marius Hack ${ }^{2}$, Alexandra Haj ${ }^{3}$, Mariana Pacurar ${ }^{1}$ \\ ${ }^{1}$ Orthodontic Department, Faculty Of Dentistry, University of Medicine and Pharmacy, \\ Targu Mures, Romania \\ ${ }^{2}$ Faculty Of Dentistry, ULBS Sibiu, Romania \\ ${ }^{3}$ Psihiatric Department, Mures County Hospital, Romania
}

\begin{abstract}
The aim of this study is to evaluate the most commonly used method and technique in fixed orthodontic treatment by making a comparison between questionnaires applied in our Orthodontic department and those applied to orthodontic specialists. Material and methods: 9 self-reported questions were used as tools for the intended evaluation, which were taken from questionnaires that were already recognized to be adequate and accurate. The conclusion of this study showed that one of the highest percentages $(52 \%)$ revealed in this study was in pumice prophylaxis. Nevertheless, a smaller number of orthodontists $(11 \%)$ said that they used Fluoridated prophylaxis paste, which was the lowest percentage of material used in polishing procedure, so the majority of orthodontists (specialists and residents) avoid to use fluoridated prophylaxis paste. $100 \%$ of orthodontists in this study used phosphoric acid having a concentration range from $35 \%$ to $37 \%$ with a demineralization time between 15 and 30 seconds, LED light cure was unanimously used by both orthodontic residents and specialists because it presents more advantages than other light cure units. A high percentage (93\%) of orthodontists used a curing time between 10 and 25 seconds for the polymerization of the primer and adhesive material, Curing time has inversely proportional with light intensity. The light intensity and radiation exposure time are directly proportional with the total amount of energy supplied. The vast majority of orthodontists $(57 \%$ ) used the low speed hand piece to remove the remnant adhesive material so as to avoid any damage to that could be caused to the enamel surface.
\end{abstract}

Keywords: questionnaires, orthodontists, phosphoric acid, light cure, enamel

\section{INTRODUCTION}

Orthodontic treatment can provide correct teeth alignment and an improved occlusal-jaw relationship. For the treatment results to be adequate, when using fixed appliances, bracket stability has to be thoroughly maintained so that orthodontists can prevent any cost increases and treatment delays $(1,2)$. It is also necessary in order to prevent any damage that can occur to the teeth enamel surface after the debonding process due to the remnant materials used to fix the brackets on the teeth surfaces. Patient's risk factors seem to be the main cause of $\mathrm{f}$ brackets failure that usually occurs while the treatment is ongoing but it can also happen after the bonding process due to by the extreme forces applied to the teeth surface (3).

Within the Orthodontics Department, of the Faculty of Dentistry, at UMF Tg. Mures, brackets bonding is considered to be the first step in all orthodontic treatment, residents doing research to find the best bonding method. Nevertheless, the existence of various factors that can influence the choice of the most adequate treatment method, making it difficult to identify a unique method for brackets bonding.

Researchers have evaluated various bonding techniques, trying to identify the factors that seemingly affect the mechanical bonding's strength, such as the condition of the enamel, the usage of 
the pumice prophylaxis, the concentration of phosphoric acid and its application duration, and the usage of different materials that can ensure the optimal conditions for increasing bonding strength and decreasing enamel surface damage (4-8).

The various factors that seem to affect the capacity to enable adequate bracket bonding strength can be found described in recent literature $(9,10)$.

Many researchers mention the importance of the pumice prophylaxis step in order to clean the teeth surfaces of any foreign materials and prepare the enamel surfaces to be treated with etching acid and then bonded by brackets. However, acquiring an appropriate cure degree is required in the optimization of composite resin properties, whether it is done physically or mechanically, the degree of light cure activated resins being directly connected to the curing time and light intensity $(11,12)$.

Two methods have been established for the preparation of enamel before bonding the brackets; the first, it is called the conventional adhesive method, it consists of three steps and three different materials: acid etch, primer bonding and adhesive bonding material $(13,14)$.

The second aims at shortening the working time and reducing the quantity of material used in bonding procedures, thus it comprises only two steps: the usage of self-etching primer on the enamel surface and then, the usage of adhesive material (15).

Light cure first started to be used in Orthodontics about 50 years ago, using different technology, wave length and intensity. It was used during orthodontic treatment with the purpose to demineralize the adhesive material and to acquire enough bonding strength of the brackets on the enamel surface. Various light cure technologies had been used throughout time, some examples being: quartz-halogen bulb, conventional halogen lights, high-intensity halogen lights or fast halogens, plasma arc units and light-emitting diodes (LED) (16).

By applying these questionnaires, we wanted to analyse the most frequent method of bracket bonding based on the materials used and find out if there are any differences between the clinical work of specialist orthodontists and that of residents.

This study aims to evaluate the most commonly used method and technique in fixed orthodontic treatment by making a comparison between questionnaires applied in our Orthodontic department and those applied to orthodontic specialists.

\section{MATERIAL AND METHODS}

9 self-reported questions were used as tools for the intended evaluation, which were taken from questionnaires that were already recognized to be adequate and accurate.

100 orthodontist specialists and residents took the questionnaire, giving their opinion. The total of 100 questionnaires was split in two equal groups:

1. Those taken by 50 orthodontist specialists from Romania and other countries (Saudi Arabia and United Arab Emirates).

2. Those taken by 50 orthodontist residents from Romania (Tg. Mures and Cluj Universities).

The questions referred to the protocol and technique used in bonding fixed appliances. The issues of interest as revealed in the answers were mainly about the pumice prophylaxis, the preparation method, the enamel work surface, the phosphoric acid concentration, the demineralization time as well as the light cure time on bonding material, considering their effects on bracket stability.

Questionnaires concerning bracket-bonding protocol

Q1) Which materials do you use during the prophylaxis procedure?

1. Pumice prophylaxis 2. Fluoridated prophylaxis paste 3. Prophylaxis without pumice

Q2) Which is the concentration (\%) of the etching material?

1. (Less than 35\%), 2. (35-38\%), 3. (More than $38 \%)$

Q3) What is the etching time?

1. (Less than 15s), 2. (15-30 s), 3. (More than 30s)

Q4) What kind of bonding primer agents do you use?

1. Conventional adhesive systems (Acid etch material, primer or bonding solution, Adhesive resin)

2. Self-etching primers (SEP)

Q5) What is the curing time of the used bonding agent?

1. (3-5s) . 2. (10-25s) . 3. (More than 30s)

Q6) What type of light cure do you use?

1. Halogen light cure 2. Plasma arc units 3. LED light cure

Q7) What light cure intensity do you use?

1. $\left(500-800 \mathrm{~mW} / \mathrm{cm}^{2}\right) 2 .\left(1,000-1,500 \mathrm{~mW} / \mathrm{cm}^{2}\right)$

3. $\left(3,200 \mathrm{~mW} / \mathrm{cm}^{2}\right)$ 
Q8What is the curing time in seconds of the composite used?

1. (3-5s) . 2. (15-25s) . 3. (More than 30s)

Q9) After debonding the brackets, how is removal of remnant adhesive material done?

1 . by using high speed handpiece 2 . by using low speed handpiece 3 . by starting with high speed handpiece, then by using low speed handpiece

\section{RESULTS AND DISCUSSION}

\section{Polishing procedure or prophylaxis step}

One of the highest percentages $(52 \%)$ revealed in this study was in pumice prophylaxis. Nevertheless, a smaller number of orthodontists (11\%) said that they used Fluoridated prophylaxis paste, which was the lowest percentage of material used in polishing procedure. As for prophylaxis without pumice, it was used by $34 \%$ of orthodontist residents used (Table 1).

TABLE 1. Polishing procedure or prophylaxis step

\begin{tabular}{|l|c|c|c|}
\hline & pumice & $\begin{array}{c}\text { without } \\
\text { pumice }\end{array}$ & $\begin{array}{c}\text { Fluoridated } \\
\text { prophylaxis paste }\end{array}$ \\
\hline residents & 14 & 34 & 2 \\
\hline specialists & 38 & 8 & 4 \\
\hline total & 52 & 37 & 11 \\
\hline
\end{tabular}

\section{DISCUSSION}

The reasoning behind applying the polishing procedure (also called prophylaxis step) before bonding the brackets is not only that of preparing the dental surface before using acid etch, but also of thoroughly cleaning and removing any microbial or foreign materials accumulated on the enamel surface (24-26). There are various types of polishing procedures using different materials:

1. Pumice prophylaxis;

2. Prophylaxis without pumice;

3. Fluoridated prophylaxis paste.

There are several studies which analysed the effect that prophylaxis material has on bonding strength and discovered that from all the prophylaxis materials only the fluoridated prophylaxis paste had an adverse effect on the bonding strength of orthodontic brackets, the reason for this happening being attributed to such small fluoridating molecules that accumulate on the enamel tubules, thus preventing the etching material to open the enamel tubules and possibly causing bonding failure (1721).

Mahajan showed that no differences were found in bonding strength between all the prophylaxis systems (22).

\section{Phosphoric acid concentration and Demin- eralization time}

As far as the second question is concerned, all orthodontist residents and specialists used the same amount of phosphoric acid concentration (from 35\% to $38 \%$ ). The differences in phosphoric acid concentration are related to the manufacture company.

$100 \%$ of orthodontists used phosphoric acid with a concentration between $35 \%$ and $38 \%$ (Table 2).

With respect to the acid etch demineralization time from the third question, in the case of both residents and specialists (100\% of orthodontists), the etching materials they were using on the enamel surface had a demineralization time between 15 to 30 seconds (Table 3 ).

TABLE 2. Phosphoric acid concentration

\begin{tabular}{|l|c|c|c|}
\hline & (Less than 35\%) & $\mathbf{( 3 5 \% - 3 8 \% )}$ & (More than 37\%) \\
\hline residents & 0 & 50 & 0 \\
\hline specialists & 0 & 50 & 0 \\
\hline total & 0 & 100 & 0 \\
\hline
\end{tabular}

TABLE 3. Demineralization time

\begin{tabular}{|l|c|c|c|}
\hline & Less than 15 s & 15-30 s & (More than 30s) \\
\hline residents & 0 & 50 & 0 \\
\hline specialists & 0 & 50 & 0 \\
\hline total & 0 & 100 & 0 \\
\hline
\end{tabular}

\section{Discussion}

All orthodontists in this study were using phosphoric acid with a concentration ranging between $35-38 \%$. Increasing its concentration proved to be risky because even though this can lead to an increased bonding strength, a higher concentration was noticed to damage the enamel surface.

When using a higher concentration of acid etching, an increase in the penetration of enamel can also be noticed, which then leads to an increase in bonding strength, as it was shown by Carstensen (23). Other studies have also confirmed his position, saying that if etching time increases, it will lead to an increased penetration on the enamel surface of the teeth $(7,13,14,27)$. Consequently, acid etch concentration and demineralization time are directly proportional with bonding strength $(28,29)$. 
A study by Carstensen (28) and another study (29) demonstrated that reducing the acid concentration from $37 \%$ to $15 \% \mathrm{H}_{3} \mathrm{PO}_{4}$ and applying it for 60 seconds had no significant difference. SEM showed that the best duration for a phosphoric acid concentration of $37 \%$ was $15 \mathrm{sec}$ and that any increase in the duration can also lead to a bigger damage in the prism.

According to several articles, when increasing phosphoric acid application time from 15 seconds to 30 seconds, differences were observed on the enamel surface $(13,14)$. A statistically important difference between the relationship of demineralization time and the bonding strength of the brackets was observed, resulting in increased bonding strength of the bracket together with the increased time of acid application $(42,44)$. Moreover, a longer duration of acid application leads to more evident composite residues on the enamel surface; in other words, increasing etching time will increase the amount of damage on the enamel surface and white spot lesions $(13,14)$.

\section{Self-etching primers (SEP) and conven- tional primer method}

The answers to the fourth question regarding self-etching primers showed that orthodontist specialists used SEP more in their clinics than residents ( $66 \%$ of specialists, $10 \%$ of residents). In addition to this, residents used the conventional adhesive system more than specialists (90\% of residents, $34 \%$ of specialists).

All in all, $62 \%$ of orthodontists used the conventional primer method and only $38 \%$ of them used self-etching primers (Table 4).

TABLE 4. Self-etching primers (SEP) and conventional primer method

\begin{tabular}{|l|c|c|}
\hline & SEP & $\begin{array}{c}\text { conventional } \\
\text { primer }\end{array}$ \\
\hline residents & 5 & 45 \\
\hline specialists & 33 & 17 \\
\hline total & 38 & 62 \\
\hline
\end{tabular}

\section{Discussion}

Mixing conditioning and priming agents into a single product is time efficient in regards to clinical work but also cost-effective, helping in the production of an individual characteristic of a new bonding system $(15,30)$. The composition of self-etching primers is a mix of phosphoric acid and methacrylate. Still, the active component of SEP is methacrylate phosphoric acid ester. The removed calcium forms a complex with the phosphate group and is incorporated into the network when the primer polymerizes. A way of ensuring that fresh primer is transported to the enamel surface is done by agitating the primer on the tooth surface $(16,19)$.

SEP has the same depth of penetration between acid etch and primer, the reason for this identical penetration resides in the fact that the use of etching is simultaneous with the use of monomer.

So, etching and monomer penetration to the exposed enamel tubules are simultaneous. This way, the depth of the etch penetration and that of the primer are basically the same. SEP is faster and more time efficient than using the conventional bonding method ( 75.5 vs. 97.7 seconds per bracket). Several studies have showed that using SEP for bonding brackets is significantly faster than using conventional acid etching (75.5 vs. 97.7 seconds per bracket), although SEP may have similar SBS values and bonding failures; however, the pumice is not recommended before using SEP. Thus, the gold standard for bonding is the conventional acid etch $(15,30)$.

The residents take part in many training courses and they are well documented in this field $(15,30)$.

\section{Light cure units, Curing time and Light cure intensity}

As for the sixth question, there are several types of light cure, nevertheless, $93 \%$ of orthodontists, both specialists and residents were using a single type of light cure, and this type was LED. Also, 7 of these specialists used LED light cure with extra power (Table 5).

Concerning the curing time used in conventional primer bonding, 43 specialists and 50 residents were using 10 to 25 seconds of light cure on primer bonding material and just 7 specialists were using it 3 to 5 seconds. All in all, $93 \%$ of orthodontists were using light cure on the bonding primer from $10 \mathrm{~s}$ to $25 \mathrm{~s}$.

$7 \%$ of all orthodontists were using LED light cure on the bonding primer between $3 \mathrm{~s}$ to $5 \mathrm{~s}$ because they used it with extra power (Table 6).

The answers to the tenth question show that 48 residents and 43 specialists used the light on the adhesive material between 10 to 25 seconds, which means that $85 \%$ of orthodontists used the light cure to polymerize the adhesive material between 10 to 
25 seconds. Meanwhile, 7 specialists were using the light cure between 3 to 5 seconds during polymerization of adhesive material (Table 7).

The changes in light cure intensity depend on the light cure unit, because light cure units have different intensities; for example, halogen light cure has an intensity from 500 to $900 \mathrm{~mW} / \mathrm{cm}^{2}$, meanwhile, LED light cure has an intensity between 1,000 and $3,200 \mathrm{~mW} / \mathrm{cm}^{2}$, depending on the manufacturing company that produces the light cure and whether it has normal or extra power.

$93 \%$ of orthodontists were using the intensity of light cure between 1,000 and $1,500 \mathrm{~mW} / \mathrm{cm}^{2}$, and these ranges of intensity exist in LED light cure with normal power. However, $7 \%$ of orthodontists used high intensity light cure $\left(3,200 \mathrm{~mW} / \mathrm{cm}^{2}\right)$ that exists in LED light cure with extra power (Table 8).

TABLE 5. Light cure unites

\begin{tabular}{|l|c|c|c|c|}
\hline & $\begin{array}{c}\text { Halogen } \\
\text { light cure }\end{array}$ & $\begin{array}{c}\text { Plasma } \\
\text { arc units }\end{array}$ & $\begin{array}{c}\text { LED light cure } \\
\text { normal power }\end{array}$ & $\begin{array}{c}\text { LED light cure } \\
\text { extra power }\end{array}$ \\
\hline residents & 0 & 0 & 50 & 0 \\
\hline specialists & 0 & 0 & 43 & 7 \\
\hline total & 0 & 0 & 93 & 7 \\
\hline
\end{tabular}

TABLE 6. Curing time of the primer

\begin{tabular}{|l|c|c|c|}
\hline & (3-5s) & $\mathbf{( 1 0 - 2 5 s )}$ & (More than 30s) \\
\hline residents & 0 & 50 & 0 \\
\hline specialists & 7 & 43 & 0 \\
\hline total & 0 & 93 & 0 \\
\hline
\end{tabular}

TABLE 7. Curing time of adhesive material

\begin{tabular}{|l|c|c|c|}
\hline & $\mathbf{( 3 - 5 s )}$ & $\mathbf{( 1 0 - 2 5 s )}$ & (More than 30s) \\
\hline residents & 0 & 42 & 8 \\
\hline specialists & 7 & 43 & 0 \\
\hline total & 7 & 85 & 8 \\
\hline
\end{tabular}

TABLE 8. Light cure intensity

\begin{tabular}{|l|c|c|c|}
\hline & $\begin{array}{c}\mathbf{5 0 0 - 8 0 0} \\
\mathrm{mW} / \mathrm{cm}^{2}\end{array}$ & $\begin{array}{c}\mathbf{1 0 0 0 - 1 5 0 0} \\
\mathrm{mW} / \mathrm{cm}^{2}\end{array}$ & $\begin{array}{c}\mathbf{3 2 0 0} \\
\mathbf{m W} / \mathrm{cm}^{2}\end{array}$ \\
\hline residents & 0 & 50 & 0 \\
\hline specialists & 0 & 43 & 7 \\
\hline total & 0 & 93 & 7 \\
\hline
\end{tabular}

\section{Discussion}

Considering the fact that light cure intensity has a direct effect on the demineralization time of the bonding agent, the variation of light intensity can range from $500 \mathrm{~mW} / \mathrm{cm}^{2}, 800 \mathrm{~mW} / \mathrm{cm}^{2}, 1,000 \mathrm{~mW} /$ $\mathrm{cm}^{2}, 1,400 \mathrm{~mW} / \mathrm{cm}^{2}$, and to $3,200 \mathrm{~mW} / \mathrm{cm}^{2}$. The bonding strength of brackets on the teeth surface is influenced by several factors, such as light cure in- tensity and radiation exposure time that have a direct proportional relationship with the total amount of energy supplied. When curing time was increased, the light intensity was decreased, which means that the two are an inversely proportional $(31,32)$.

\section{The usage of the dental chair light during brackets bonding process}

As far as the dental chair light is concerned, most residents avoided to use the chair light during bonding procedure, 28 residents did not use the light chair during bonding, and 22 residents only used the chair light when they needed a clear vision in the oral cavity especially in the posterior teeth.

An increase in the rate of orthodontists that used chair light during bonding the brackets was noticed in the case of experienced specialists. 16 orthodontist specialists used light chair during brackets bonding, 29 of orthodontists specialists used chair light to have better visual access to the oral cavity, if needed, and 15 orthodontist specialists avoided to use the chair light during the bonding procedure.

$51 \%$ of all orthodontists in this study used the chair light when it was necessary in the middle of the bonding procedure, and $43 \%$ of orthodontists avoided to use the light chair during the bonding procedure (Table 9).

TABLE 9. The usage of the light of dental chair during brackets bonding process

\begin{tabular}{|l|c|c|c|}
\hline & allowed & some time & never \\
\hline residents & 0 & 22 & 28 \\
\hline specialists & 16 & 29 & 15 \\
\hline total & 16 & 51 & 43 \\
\hline
\end{tabular}

It is mentioned in several studies that the chair light has a direct effect through polymerization of the brackets during brackets bonding, and for this reason the experience of orthodontists plays an important role during brackets bonding, because if the orthodontist needs a longer working time during brackets bonding, then it is suggested to avoid using chair light. However, using chair light during brackets bonding may increase the polymerization rate of the adhesive material (33).

\section{Removing remnant adhesive material}

$57 \%$ of orthodontists used low speed handpiece to remove remnant adhesive material after debonding the brackets (32 residents, and 24 specialists). On the other hand, only 13 specialists used high- 
speed handpiece to remove the remnant adhesive material. Nevertheless, 18 residents and 13 specialists started with high-speed handpiece and then they used low speed handpiece to remove the remnant adhesive material (Table 10).

TABLE 10. Removing remnant adhesive material

\begin{tabular}{|l|c|c|c|}
\hline & $\begin{array}{c}\text { high } \\
\text { speed } \\
\text { handpiece }\end{array}$ & $\begin{array}{c}\text { low } \\
\text { speed } \\
\text { handpiece }\end{array}$ & $\begin{array}{c}\text { starting with high } \\
\text { speed handpiece } \\
\text { then using low speed } \\
\text { handpiece }\end{array}$ \\
\hline residents & 0 & 32 & 18 \\
\hline specialists & 13 & 24 & 13 \\
\hline total & 13 & 57 & 31 \\
\hline
\end{tabular}

\section{Discussion}

An important clinical problem, especially after the evaluation of mechanical and physical properties, seems to be removing the remnant adhesive material from the tooth surface after debonding the brackets. Whenever the adhesive material is not completely removed, it may lead with time to discoloration and even entrap plaque. Multiple studies note different techniques to remove the remnant adhesive material.

The most common method is using a low speed hand piece with Tungsten Carbide bur; another acceptable method is using a high-speed hand piece with a diamond bur $(34,35)$.

It is recommended to use at first a high-speed hand piece with diamond or Tungsten Carbide burs to remove the bulk of the remnant adhesive, then to use the low speed hand piece when the bur starts to be more close to the enamel surface, the required speed to remove the remnant adhesive material with low speed hand piece being of 30.000 rounds per minute (35).

\section{REFERENCES}

1. Finnema K.J., Ozcan M., Post W.J., Ren Y., Dijkstra P.U. In-Vitroorthodontic Bond Strength Testing: A Systematic Reviewand Meta-Analysis. Am J Orthod Dentofacial Orthop. 2010; 137:615-622.

2. Mandall N.A., Millett D.T., Mattick C.R., Hickman J., Worthington H.V., Macfarlane T.V. Orthodontic Adhesives: A Systematic Review. J Orthod. 2002; 29, 3:205-10.

3. Katona T.R. Stresses Developed During Clinical Debonding Of Stainless Steel Orthodontic Brackets. Angle Orthod. 1997; 67:39-46.

4. Lopes G.C., Thys D.G., Klaus P., Oliveira G.M., Widmer N. Enamel Acid Etching. Compend Contin Educ Dent. 2007; 28: 18-24.
As a technique to remove the adhesive, it is suggested to move the high or low speed hand pieces only to one direction (34).

I avoid using water with a low speed hand piece when the bur gets closer to the enamel surface in order to facilitate vision and thus remove only the adhesive material.

\section{CONCLUSION}

The majority of orthodontists (specialists and residents) failed to use fluoridated prophylaxis paste so as to prevent brackets failure and pumice prophylaxis paste was used by $52 \%$ of them.

$100 \%$ of orthodontists in this study used phosphoric acid having a concentration range from 35\% to $37 \%$ with a demineralization time between 15 and 30 seconds.

Most residents (97.5\%) used the conventional primer method and $66 \%$ of specialists used Self-etching primers (SEP) in order to be more time-efficient in their work.

LED light cure was unanimously used by both orthodontic residents and specialists because it presents more advantages than other light cure units.

A high percentage (93\%) of orthodontists used a curing time between 10 and 25 seconds for the polymerization of the primer and adhesive material.

Curing time has inversely proportional with light intensity. The light intensity and radiation exposure time are directly proportional with the total amount of energy supplied.

The vast majority of orthodontists (57\%) used the low speed hand piece to remove the remnant adhesive material so as to avoid any damage to that could be caused to the enamel surface.

Conflict of interest: none declared Financial support: none declared

5. Osorio R., Toledano M., Garcia-Godoy F. Bracket Bonding With 15- Or 60 Second Etching And Adhesive Remaining On Enamel After Deboning. Angle Orthod. 1999; 69: 45-8.

6. Bishara S.E., Gordan V.V., Vonwald L., Olson M.E. Effect Of An Acidic Primer On Shear Bond Strength Of Orthodontic Brackets. Am J Orthod, 1998; 114:243-7.

7. Wang W., Chau T.Z. Bond Strength With Various Etching Times On Young Permanent Teeth. Am J Orthodontics Dentofacial Orthop. 1991; 100: 72-9.

8. Gardner A., Hobson R. Variations In Acid-Etch Patterns With Different Acids And Etch Times. Am J Orthod Dentofacial Orthop. 2001; 120: 64-7. 
9. Mónicamendes Jaime Portugal, Sofia Arantes Oliveira, Pedro Mesquita. Shear Bond Strength Of Orthodontic Brackets To Fluorosed Enamel. Medicina Dentária E Cirurgia Maxilofacial. 2014; 55, 2: 73-77.

10. Godinho J.O. Comparison Of Twoself-Etching Primers And Effect Of Saliva Contaminationon Shear Bond Strength Of Orthodontic Brackets. Rev Portestomatol Cir Maxilofac. 2007;48:197-203.

11. Leprince J.G., Palin W.M., Hadis M.A., Devaux J., Leloup G. Progressin Dimethacrylate-Based Dental Composite Technology Andcuring Efficiency. Dent Mater. 2013; 29:139-56.

12. Rueggeberg F.A., Caughman W.F., Curtis J.W. Jr. Effect Of Lightintensity And Exposure Duration On Cure Of Resin Composite. Oper Dent. 1994; 19:26-32.

13. Krisztina Mártha, Alexandru Ogodescu, Cristina Bica, Emilia Ogodescu, Irina Zetu. Comparative Sem Analysis Of The Effect Of Acidic Monomers. Rev. Chim. Bucharest. 2013; 64, 8: 875-875.

14. Krisztina Mártha, Alexandru Ogodescu, Irina Zetu, Emilia Ogodescu, Mariana Pacurar. The Effect Of Phosphoric Acid Etching Application Time. 2013. REV. CHIM. Bucharest. 64, 9: 982-6.

15. K. House A.J., Ireland M.S. An Investigationin To The Use Of A Single Component Self-Etching Primer Adhesive System For Orthodonticbonding: A Randomized Controlled Clinical Trial. British Orthodontic Society. 2006;33: 38-44.

16. Grajower R., Glick A., Gedalia I., Kochavi D. Tensile Strength Of The Bond Between Resin To Enamel Etched With Phosphoric Acid Containing Fluoride. J Oral Rehabil. 1979; 6:267-272.

17. Lee H., Stoffey D.J.,Orlowski M.L., Swartz D. Ocumpaugh, K. Neville. Sealing Of Developmental Pits And Fissures Effects Of Fluoride On Adhesion Of Rigid And Flexible Sealers. J Dent Res. 1972; 51:191-201.

18. Low T.J., Von Fraunhofer A., Winter G.B. Influence Of The Topical Application Of Fluoride On The In Vitro Adhesion Of Fissure Sealants. J Dent Res. 1977; 56:17-20.

19. Brantley W.A., Eliades Thieme T. Stuttgart. Orthodontic Materials. Scientific and Clinical Aspects. 2001; 91: 310.

20. Sarah Al-Twaijri, Grace Viana, And Ana K. Bedran-Russo. Effect Of Prophylactic Pastes Containing Active Ingredients On The Enamel-Bracket Bond Strength Of Etch-And-Rinse And Self-Etching Systems. The Angle Orthodontist. September , 2011, 81, 5: 788-793.

21. Mahajan M., Singla A., Saini S.S. Comparative Evaluation Of Different Prophylaxis Pastes On Shear Bond Strength Of
Orthodontic Brackets Bonded With Self Etch Primer: An In-Vitro Study. J Indian Orthod Soc, 2015;49:32-6.

22. Carstensen W. Effect Of Reduction Of Phosphoric Acid Concentration On The Shear. Bond Strength Of Brackets. Am J Orthod Dentofacial Orthop. 1995 Sep; 108:274-7.

23. William R. Proffit, Henry W. Fields, J. D. Contemporary Orthodontics Fourth Edition. 2007; 11: contemporaray orthodontic appliances.

24. Bis Samir E. Bishara. Textbook Of Orthodontic. 2001; 3: appliances.

25. Lill D.J., Lindauer S.J., Tüfekçi E., Shroff B. Importance Of Pumice Prophylaxis For Bonding With Self-Etch Primer. J Orthod Dentofacial Orthop. 2008; 133(3):423-6.

26. Chow L.C., Brown W.E. Phosphoric Acid Conditioning Of Teeth For Pit And Fissure Sealants. J. Dent Res. 1973; 52 (5): 1158.

27. W. Carstensen. Effects Of Reduced Phosphoric Acid Concentration On Shear Bond Strength. Am. J. Orthodontics. 1995; 108 (2): 274-277.

28. Sadowsky P.L., Retief D.H., Cox P.R., Hernï Ndez-Orsini R., Rape W.G., Bradley E.L. Effects Of Etchant Concentration And Duration On The Retention Of Orthodontic Brackets. An In Vivo Study. Am J Orthod Dentofacial Orthop. 1990; 98: 417-21.

29. Padhraig S. Fleming, Ama Johal, Nikolaos Pandis A. Self-Etch Primers And Conventional Acid-Etch Technique For Orthodontic Bonding. A Systematic Review And MetaAnalysis. Am J Orthod Dentofacial Orthop. 2012; 142(1):8395.

30. Ahmet Yagci, Suleyman Kutalmıs Buyuk. Shear Bond Strength And Temperature Rise Of Orthodontic Brackets Bonding By Using A New 3-Second LED Mode. Turkish J Orthod. 2013. 26:45-50.

31. Mavropoulos A., Staudt C.B., Kiliaridis S., Krejci I. Light Curing Time Reduction: In Vitro Evaluation Of New Intensive Lightemitting Diode Curing Units. Eur J Orthod. 2005; 27:408-412.

32. Chachada A., Hazarey P.V., Shinde V., Atulkar M., Dalvi P., Speedie A., Bhayade S. Effect Of Dental Chair Light On Shear Bond Strength Of Composite Used For Bonding Of Brackets - An In Vitro Study. Int J Oral Health Med Res, 2015; 2(4):22-25.

33. Bis Samir E. Bishara. Textbook Of Orthodontic. 2001; 3: appliances.

34. Https://Www.Pocketdentistry.Com/Adhesives-And-BondingIn-Orthodontics/ 